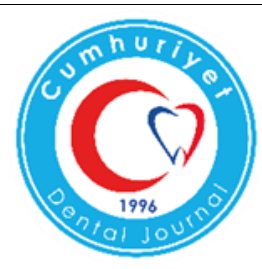

\title{
METHODS AND DEVICES USED IN COLOR DETERMINATION
}

\author{
Renk Belirlenmesinde Kullanılan Yöntem ve Cihazlar
}

Ruhsan MÜDÜROĞLU ${ }^{1}$, Tuğba ÇONGARA KIVRAK ${ }^{2}$, Adil NALÇACI ${ }^{2}$

\begin{abstract}
Makale Kodu/Article Code $\quad$ : 309148
Makale Gönderilme Tarihi $\quad: 26.04 .2017$

Kabul Tarihi

$: 06.06 .2017$
\end{abstract}

\begin{abstract}
Nowadays with the advanced technological developments, patients come to dentist to get healthy and esthetic smile. Most noticeable factor in a beautiful smile is shade. Accurate shade selection is seen to be important criteria for esthetic assessments. Descripting and transferring the color, perceiving available systems and making accurate measurements are under the responsibility of dentists. A lot of factors must be considered when selecting shade. In the last years, it's observed that there is an increase of scientific researches about color and new advances about measurements and their assessments. Re-evaluation of new advances with the current knowledge is important for dentist. The aim of this review is to give information, regarding methods used in selecting shade and factors which affect these methods.
\end{abstract}

Key words: Color, color selection systems, esthetic

\section{ÖZ}

Günümüzde ilerleyen teknolojik gelişmelerle birlikte hastalar sağlıklı ve estetik bir gülüş için diş hekimine gelmektedir. Güzel bir gülüşte dikkat çeken en önemli faktör ise renktir. Estetik değerlendirmelerde doğru renk seçimi de başarının önemli bir kriteri olarak karşımıza çıkar. Renk kavramını tanımlamada ve aktarmada mevcut sistemleri bilmek ve doğru ölçümler yapmak diş hekiminin sorumluluğu altındadır. Renk seçiminde dikkat edilmesi gereken birçok faktör vardır. Son yıllarda renk konusunda bilimsel çalışmalarda bir artış yaşanırken ölçüm ve değerlendirmelerde de yeni gelişmeler olduğu gözlemlenmektedir. Yeni gelişmeleri mevcut bilgiler rehberliğinde yeniden değerlendirmek diş hekimleri için önem taşımaktadır. Bu derlemenin amacı renk seçiminde kullanılan yöntemler ve bu yöntemleri etkileyen faktörler hakkında bilgi vermektir.

Anahtar Kelimeler: Renk, renk sistemleri, estetik

${ }^{1}$ Uzm. Dt. Restoratif Diş Tedavisi, Serbest Çalışan, Ankara.

${ }^{2}$ Dt. Ankara Üniversitesi Diş Hekimliği, Diş Hastalıkları ve Tedavisi Anabilim Dalı. 


\section{GíRIŞ}

Estetik bir restorasyonun amac1; morfolojik, optik ve biyolojik uyumun sağlanmasıdır. Estetik diş hekimliği, esas olarak diş hekimi ve teknisyenin sanatsal kabiliyetine bağlı olmasına rağmen konuyla ilgili bilimsel prensiplerin bilinmesi de son derece önemlidir. Günümüz diş hekimliğinde kaybolan dokuların rehabilitasyonu için yapılan restorasyonlar, doğal dişlerin rengi ve formuyla uyum içinde olmalıdır. Estetik bir restorasyonun yapımında, renk seçimi kritik bir basamaktır. Rengin en mükemmel şekilde seçilmesi hastanın estetik beklentileri açısından çok önemlidir. ${ }^{1}$

$\mathrm{Bu}$ derlemenin amacı renk seçimi için dikkat edilmesi gereken noktaların güncel literatür desteği altında vurgulanması ve geliştirilen cihazların incelenmesidir.

Diş renginin belirlenmesi için kullanılan yöntemin basit, çabuk ve tekrarlanabilir olması gerekir. Doğal diş ve renk skalalarındaki renklerin analiz edilmesi için çoğunlukla iki yöntem kullanılır:

> Konvansiyonel Yöntem: Diş renginin gözle belirlenmesi

> Dijital Renk Ölçümü ${ }^{2}$

\section{Diş Renginin Gözle Belirlenmesi (Konvansiyonel Yöntem) (Görsel Ölçüm)}

Diş hekimliğinde renk belirlenmesinde en sik kullanılan yöntem, diş renginin, sabit diş rengi skalaları ile karşılaştırılması yöntemidir. ${ }^{3} \mathrm{Bu}$ yöntemde diş ve skala aynı 1şık kaynağı altında subjektif olarak karşılaştırılır. Işık kaynağı, tecrübe, yaş, insan gözünün yanılabilirliği ve fizyolojik etkenler (renk körlüğü gibi) genel değişkenler tutarsızlığa neden olabilir. ${ }^{2}$

Renk seçimi yaparken 1şık kaynağı, cisim ve gözlemci etkileşimi önemlidir. Bunlardan en önemli faktör 1şık kaynağıdır. Bir eşyanın algılanan rengi, eşyanın maruz kaldığı ışığın türü, diğer renkli objelerle olan ilişkisi ve gözlemcinin değerlendirme yeteneğinden etkilenir. Metamerizm bir cismin renginin 1şık kaynağına bağlı olarak farklı görünmesi olgusudur. Dolayısıyla bir diş farklı ortamlarda farklı renklerde görülebilir. ${ }^{4,5}$

Bir cisim 1sıtıldığı zaman renk değişimine uğrar. Renkler arası geçişlerde sıcaklık değişimleri olur ve buna bağlı olarak her renge ait karakteristik bir renk sıcaklığ 1 bulunabilir. Renk sıcaklığı Kelvin (K) olarak ifade edilir. Gün ışığının renk sıcaklığı 5500 K'dir. Bu renk sıcaklığı kırmızı, mavi ve yeşili eşit oranda içerir ve beyaz rengi oluşturur. Güneş 1şığ zamana, havanın durumuna veya kirliliğine bağlı olarak farklı dalga boylarında yayılır ve gün boyunca önemli derecede değişebilir. ${ }^{6}$

Diş skalalarındaki renkler doğal diş renklerinin hepsini kapsamamaktadır, dolayısıyla hastayı veya hekimi memnun edecek bir renk seçilmesi son derece zordur. ${ }^{7}$ Ayrıca bu yöntemin birçok başka dezavantajı vardır. Bunlar diş hekimi ile diş teknisyeni arasındaki iletişimde kullanılabilecek standardize çeşitliliğin limitli olması, renklerin karşılaştırılmasında diş hekimleri arasında ve diş hekiminin yapmış olduğu kendi seçimleri arasında farklılıkların olabilmesi ve elde edilen sonuçların CIE Lab renk skalasına dönüştürülememesi olarak sayılabilir., ${ }^{2,3,8}$

Renk seçerken gün 1şı̆̆ını taklit eden floresan lambaların kullanılması alternatif yöntem olarak kabul edilmektedir. Ayrıca ortam 1şığının yetersiz olduğu durumlarda yabancı 1şık kaynaklarını kullanmak da daha güvenilir sonuçlar almak için önerilebilir. $\mathrm{Bu}$ amaçla bazı firmaların ürettiği pil ile çalışabilen ve taşınabilmesi kolay olan gün 1şığını taklit eden aletler mevcuttur. ${ }^{4}$

Görsel Renk Tespitinin Avantajları: Renk tespit süresi çok kısadır ve maliyeti düşüktür.

Görsel Renk Tespitinin Dezavantajları: Renk skalalarındaki mevcut renkler yetersizdir. Diş hekimleri arasında ve aynı bireyde günün farklı saatlerinde seçilen renkte tutarsızliklar olmakta, standardizasyon sağlanamamaktadır. 
Elde edilen sonuçları CIE L*a*b* renk sisteminde göstermek olanaksızdır. ${ }^{3,9}$ Aynı üretici tarafından oluşturulmuş renk skalalarında birebir aynı olmayan sonuçlar bildirilmiştir. ${ }^{10}$ Renk seçiminde cinsiyetin de etkisi olduğu gözlenmiş ve erkek diş hekimlerinin \%9.3ünün renk algilama defektine (renk körlüğü) sahip olduğu ortaya konmuştur. ${ }^{11}$

\section{Dijital Renk Ölçümü (Renk Ölçüm Cihazları ile Ölçüm)}

Renk ölçüm cihazlarının kullanımı ile daha objektif, tekrarlanabilir ve hızlı ölçümler yapılabilmektedir. Böylece görsel yolla yapılan renk seçimine nazaran potansiyel bir avantaj sağlanmaktadır. ${ }^{2} \quad$ Renk ölçüm cihazları günümüzde kolorimetre, spektroradyometre, spektrofotometre ve dijital kameralar olmak üzere 4 kategoride incelenir. ${ }^{12}$

$\mathrm{Bu}$ cihazlar yüzeyde yaptıkları ölçüm alanına göre ikiye ayrılmaktadır: Spot ölçüm cihazları (SM-Spot measurement) ve tam yüzey ölçümü yapan cihazlar (CTM-Complete tooth measurement). Dişin renk haritas1 çıkarılmak istendiğinde SM cihazları ile birçok bölgeden ölçüm yapma zorunluluğu doğar. CTM cihazları tek bir görüntüde bütün renk haritasını vermeleri bakımından daha avantajlıdırlar. ${ }^{13}$ Günümüzde kullanılan renk ölçüm cihazları Tablo 1'de gösterilmiştir.

Tablo 1: Günümüzde kullanılan renk ölçüm cihazları

\begin{tabular}{lll}
\hline Sistem & Üretici Firma & Tipi \\
\hline Minolta CR-321 & Minolta C., Japan & Kolorimetre \\
Shade Eye NCC & Shofu Dental, California & Kolorimetre \\
Shade Eye Ex & Shofu Dental, Japan & Kolorimetre \\
EasyShade & Vident, California & Spektrofotometre \\
ShadeScan & Cynovad, Canada & Dijital renk analizörü/ Kolorimetre \\
ShadeVision & X-Rite, Inc., Michian & Dijital renk analizörü/ Kolorimetre \\
SpectroShade MHT & Niederhasli, Switzerland & Dijital renk analizörü/ Spektrofotometre \\
Clearwatch & Smart Technology, Oregon & Dijital kamera/ software \\
\hline
\end{tabular}

\section{Kolorimetreler}

Standart bir renk kalibrasyonuna dayanarak rengi tespit edilecek objedeki renk verilerini analiz eden cihazlardır. Bu cihazlar üç uyaranlı $\mathrm{x}, \mathrm{y}, \mathrm{z}$ değerlerini veya CIE L*a*b* değerlerini verirler. CIE $\mathrm{L}^{*} \mathrm{a} * \mathrm{~b} *$ sistemini kullanan cihazların çalışma prensibi belirli açıda ışın gönderip, sabit bir açıyla geri dönen ışınların yansıma değerlerini ölçme esasına dayanmaktadır. Yüzey renklerinin ölçülmesi için kolorimetre içerisinde insan gözündeki kon tipi hücrelere benzer olarak üç farklı sensor bulunmaktadır. Dedektör içinde yer alan bu sensörler, CIE x y z sistemine yakın sonuç vermek için yerleştirilmiştir. ${ }^{12,14}$

Kolorimetre tristimulus değerlerini ölçer; bu, insan gözünün renkleri algılama işlemini matematiksel olarak stimule edebilmek gayesiyle yapılan birtakım hesaplar sonucunda elde edilen $\mathrm{X}, \mathrm{Y}, \mathrm{Z}$ renk koordinat bilgisidir, ayrıca 1şığı görünür spektrumda kırmızı, yeşil ve mavi alanlar olarak filtreler. ${ }^{15}$

Renk değerlendirilmesi için tasarlanmış ilk cihaz 1980'li yılların başlarında tanıtılmış olan 'Chromascan' (Sterngold, Stamford, CT, USA) dir. Ancak bu cihazın sınırlı hassasiyeti ve kullanım zorluğu nedeniyle çok başarılı olunamamıştır. ${ }^{8}$

ShadeEye NCC Chromametre (Shofu, Japan) ise, ikinci jenerasyon modern dental üç uyaranlı kolorimetrelerindendir. Kolorimetrelerdeki 1şığın yansıma ve dağılma sorunlarına ilişkin problemleri elimine etmek amacı ile ShadeEye NCC sisteminde rengi ölçülecek olan materyalin cinsinin seçilebileceği seçenekler olmalıdır. Kalibrasyon öncesinde hangi materyalin rengi ölçülecekse cihaz ona göre ayarlandığında, matematiksel algoritmalar o cisme göre ölçüm yapmaktadır. ${ }^{12}$

ShadeVision (X-Rite, Grandville, MI) ise bir görüntüleme kolorimetresidir. 3 ayr1 veritabanı kullanılarak tüm diş görüntüsü elde edilir, bunlar: gingival, orta ve insizal üçlüdür. Sanal deneme özelliği, yapım aşamasında rengin tekrarlanabilirliğini sanal olarak test etmeye olanak sağlar. ${ }^{12}$

ShadeRite Dental Vision System (Shaderite Inc. Michigan, USA) Dijital 
görüntüleme ve kolorimetreyi birleştiren diğer bir sistemdir. ${ }^{16}$

Kolorimetrelerin avantajlarl: Kolorimetre, spektroradyometre ve spektrofotometrelerden daha kolay kullanılır ve daha küçük aletlerdir. Diş hekimliğinde kullanılan kolorimetreler, in vivo ve in vitro çalışmalarda oldukça başarılı bulunmuştur. Fiyatları daha uygundur. ${ }^{8,16}$

Kolorimetrelerin Dezavantajlarl: Bu cihazlar düz yüzeylerde ölçüm yapmak için tasarlanmıştır. Ancak dişler çoğunlukla düz yüzeye sahip değildirler. Dar açıklığa sahip olan cihazlarda 'edge-loss' diye tabir edilen renk ölçüm yapılan nesneden yansıyan ışığın cihaza tam olarak dönememesi gibi problemler yaşanmaktadır. ${ }^{17}$ Kolorimetrede filtrelerin kısa sürede eskimesi, cihazın sürekli kullanılabilirliğini etkilemektedir. Trikromatik kolorimetrelerin uzun dönemde tekrarlanabilirlik özelliği daha düşüktür bu yüzden farklı dönemlerde yapılan ölçümler birbirini tutmayabilir. Metamerizmi değerlendirmek için kullanılmamaktadırlar. Translusent materyallerin renklerinin belirlenmesinde ise 1şığı kırılarak dağılmasından dolayı sonuçlarda problem yaşanabilir. ${ }^{18}$ Kolorimetreler spektral yansımayı kaydetmemektedirler ve filtrelerin eskimesinden dolayı hassasiyeti etkilendiğinden, spektrofotometrelerden daha az güvenilirdirler. ${ }^{15}$

\section{Spektroradyometreler}

Radyometrik ölçümlerde parlaklığg belirlemek üzere tasarlanmış cihazlardır. $\mathrm{Bu}$ birimler parlaklık spektrumunu lux gibi aydınlatma miktarını gösteren birimlerle açıklar. Renkleri, transparanlığ 1 yansıtarak veya yayılan 1 şı $\breve{g}_{1}$ projektör yardımıyla beyaz ekrana ileterek ölçer. ${ }^{19}$

Spektroradyometreler, radyometrik değerlerin ölçümü için tasarlanmış ve renk üretimi uygulamalarında sik kullanılan cihazlardır. Spektroradyometrik yöntemlerde temel dayanak ise objelerin elektromagnetik bölgelerde kendine özgü bir yansıma (reflectance/ radiance) değerinin bulunmasıdır. $\mathrm{Bu}$ yansıma değerleri objeye renk, doku, parlaklık ve görünüş gibi özellikleri veren kimyasal yapısından kaynaklanmaktadır. Radyometrik enerji, görünür 1 ş1k spektrumunun üzerinde $5,10,20 \mathrm{~nm}$ aralıklarda ölçülmektedir. ${ }^{20}$

Spektroradyometrenin avantajları: Görsel yolla renk belirlenirken oluşturulan aynı gözlem koşullarında, materyale değmeden, hem kendisi hem de yüzeyi parlak olan cisimlerin renk ölçümlerinin yapılabilmesidir. ${ }^{20}$ Spektroradyometreler ile 'edge loss' etkisi ortadan kaldırılmaya çalışılmıştır; çünkü bu sistemde 1şık kaynağı, spektroradyometre ve obje arasında açıklık bulunmamaktadır. $^{21}$ Dental araştırmalarda spektroradyometreler diş renginin veya seramik kor yapıların translusensliğinin belirlenmesinde kullanılmaktadır., ${ }^{9,22}$ Rengin (yüzey ve yarı aydınlık) tüm formlarını ölçer. $\mathrm{Bu}$ da monitörize edilen görüntünün, baskıyla yapılacak olan eşleştirilmesi için önemlidir. ${ }^{12}$

Spektroradyometrenin dezavantajları: :̈̈lçüm pozisyonunda meydana gelebilecek ufak bir değişiklik sonuçlarda farklılık yaratabileceğinden, ölçümler büyük bir dikkat ile yapilmalıdır.

\section{Spektrofotometreler}

Spektrofotometrelerin en yaygin kullanım alanı, yüzey renklerinin ölçülmesidir. İçerisinde bir monokromatör, dedektör ve 1 ş1k kaynağ1 bulunur. Spektrofotometreler, birçok dalga boyunda ölçüm yapabilen sensörlerle donatılmışlardır. İnsan gözünün tespit edemeyeceği renkleri bu sensörler sayesinde algılayabilirler. Çalışma prensipleri; örnekten yansıyan ışığın, beyaz bir yüzeyden yansıyan 1şı̆̆a oranının ölçülmesi işlemine dayanmaktadır. Cihazın içinde beyaz 1şığı 10$20 \mathrm{~nm}$ dalga boyları arasinda bir spektruma ayıran prizma bulunmaktadır. ${ }^{23}$ Görünür 
spektrumda $1-25 \mathrm{~nm}$ aralıklarında bir cisimden yansıyan 1şık enerjisi miktarını ölçer. ${ }^{24}$

Spektrofotometreler daha profesyonel alanlarda, bilimsel çalışmalarda, kalite kontrolünde ve rengin tarif edilmesinde kullanılmaktadırlar. ${ }^{25}$ Diş hekimliğinde ise; restoratif rezinlerin, tam protez dişlerin, porselen restorasyonların, renk anahtarlarının, dental materyallerin renklerinin sayisal ifadelerini bulmak ve renkli iki cismin arasındaki renk farkını değerlendirmek amacıyla kullanılmaktadır. ${ }^{26}$

Birçok spektrofotometre nokta ölçümü yapmaktadır. Ancak son dönemde tüm diş yüzeyinden tek bir ölçüm yapan laminar tip spektrofotometreler geliştirilmiştir. Schmitter ve ark. (2008) laminar bir spektrofotometrenin (Shade Pilot, DeguDent, Hanau- Wolfgang, Germany) gözlemciler arası fark bakımından klinik değerlendirmelerini yapmışlar ve son derece güvenilir olduğu sonucuna varmışlardır. Özellikle L* değerleri açısından SM tiplere göre belirgin başarı elde edildiğini bildirmişlerdir. ${ }^{19}$

İnsan dişlerinin renk analizinde, görsel ölçüm ve spektrofotometrik renk analizi kullanılarak yapılan bir çalışmada, cihaz kullanımının daha doğru ve uygulanabilir bir renk analizi yöntemi olduğu belirtilmiştir. ${ }^{27}$

Crystal Eye (Olympus, Tokyo, Japan) geleneksel spektrofotometrelerin faydalarını dijital fotoğrafçılıkla birleştirmiştir. Optik ve resim işleme sürecinin gelişiminde bu ürün rengi ve renk tonunu eşleştirmede geleneksel spektrofotometreyle kiyaslandığında daha doğru ve basittir. Crystal Eye'ın klinik etkinliği değerlendirilmiş ve konvansiyonel renk seçim sistemine göre çok daha iyi renk uyumu yakaladığı, $\Delta \mathrm{E}$ değerlerinin daha düşük olduğu bulunmuştur. ${ }^{28}$ Crystal Eye spektrofotometrenin, farklı gözlemci ve 1şık kaynakları kullanıldığı durumlarda bile tutarlı sonuçlar verdiği bulunmuştur. ${ }^{29}$
SpektroShade Micro (MHT, Niederhasli, Switzerland) görüntüleme spektrofotometresidir. Bir dijital kamera ve LED spektrofotometre kombinasyonudur. LCD dokunmatik ekranında gösterilen diş pozisyonlandırma rehberlik sistemi renk ölçümü sırasında kullanılır. Görüntüler ve sanal veriler hafizaya kaydedilebilir ve başka bir bilgisayara aktarılabilir. ${ }^{30}$

Vita Easyshade Compact (Vita Zahnfabrik, Bad Sackingen, Germany); kablosuz, küçük, taşınabilir, uygun fiyatlı, pilli ve temaslı tipte spektrofotometredir. $\mathrm{Bu}$ spektrofotometre renk analiz sürecine yardım etmek için yeterli renk tonu bilgisini sağlar. Vita Easy Shade Compact'ta farklı ölçüm modları mümkündür: Tek diş modu, diş alanı modu (servikal, orta ve insizal tonlar), restorasyon renk doğrulaması (aydınlık, chroma ve hue kıyaslamalarını içerir) ve renk tonu ucu (deneme modu). Vita Classic veya Vita 3D Master renk skalalarıyla uyumlu sonuçlar elde edilir. Vita Easyshade Compact birçok fotometre arasında en fazla tekrarlanan renk belirlemesi ile güvenilir bir aygıttır. ${ }^{22,31,32}$

Araştırmacılar Vita Easy Shade Compact ve Spectro Shade Micro ile yapılan renk ölçümlerinin son derece güvenilir ve tekrarlanabilir olduğunu, bu cihazların diş rengi belirlemek ve tedavi sonrası meydana gelen renk değişimlerini incelemek amaciyla klinik olarak kullanılabileceğini belirtmişlerdir. ${ }^{31,32,33}$

Spektrofotometrelerin Avantajlarl: Farklı renk ölçüm cihazlarını güvenilirlik ve tekrarlanabilirlik olarak karşılaştırdıkları çalışmanın sonucunda spektrofotometrelerin (Shade Vision ve Vita Easy Shade), kolorimetreler ile karşılaştırıldıklarında daha güvenilir ve kesin sonuç verdiğini belirtmişlerdir. ${ }^{15}$ Metamerizmi ayırt edebilmek amacı ile de kullanılabilirler. ${ }^{25}$

Spektrofotometrelerin Dezavantajlarl: Spektrofotometreler kolorimetrelereden daha 
kapsamlıdırlar, ancak klinik olarak uygulamaları kisitlı olduğundan kolorimetrelerin diş hekimliğinde kullanımı daha kapsamlıdır ve in vivo kullanımı zordur. ${ }^{17}$ Pahalı ve komplikedirler. ${ }^{25}$

\section{Dijital Kameralar}

Dijital kameraların kullanımı renk ölçümünde ve hekim ile laboratuvar iletişiminde son yıllarda oldukça popüler hale gelmiştir. RGB cihazları diye de adlandırılan bu cihazlar teknolojik sistemler içinde en basit olanlardır. Standart 1şıklandırma koşulları altında güvenilir renk ölçümüne olanak tanırlar. ${ }^{34}$

Yöntem; klinikte çekilen fotoğraf görüntüsünün, kameranın bağlı olduğu bilgisayarda analiz edilmesine bağlıdır. Film üzerinde $1 s ̧ 1 \mathrm{k}$ odaklanması ve kimyasal reaksiyon yerine, dijital fotoğraf makineleri görüntüyü algılayıcı (CCD) ile yakalarlar. CCD'ler milyonlarca sayıdaki küçük 1şı̆̆a hassas elemanlar (fotosit) içerirler. Her bir fotosit üzerine gelen toplam 1şığa cevap verebilir. Tüm renklere sahip bir görüntü elde etmek için alıcılar (sensör) 1şı̆̆ın temeli olan üç renkte bakabilmek için filtreler kullanılır. $\mathrm{Bu}$ cihazlarda üç ayrı renk her bir piksele kaydedilebilir. ${ }^{35}$

İstenilen objenin görüntüsü dijital bir kamera ile alındıktan sonra, kameranın bağlı olduğu bilgisayar bu değerleri CIE L*a*b* cinsinden ifade etmektedir. Sistem; dijital kameranın dışında, bağlı olduğu bilgisayar, görüntüyü yakalayan bir sürücü, bilgisayar programı ve renk sensöründen meydana gelmektedir. ${ }^{36}$

Birçok alıcı video veya dijital tipte kamera kırmızı, yeşil ve mavi görüntü bilgilerini elde eder, renk görüntüsü elde etmek için bunlardan yararlanılır. $\mathrm{Bu}$ RGB renk modeli kırmızı, yeşil ve mavi ışı̆̆ın çeşitli yollarla birbirine eklenerek geniş bir renk sırası oluşturulmasına katkı sağlar. Dijital kameralar elektronik renk seçiminde en temel yaklaşımdır. ${ }^{37}$
ClearMatch (Smart Technology, Hood River, OR) yüksek çözünürlükte dijital görüntüler kullanan bir yazılım sistemidir ve renk tonlarını dişle bilinen referans tonlarla kıyaslar, ayrıca endüstriyel standartlarda renk tonu rehberliği içerir. ${ }^{30}$

Dijital görüntüleme sistemleri diş rengi belirlemede giderek popüler olmaktadır. $\mathrm{Bu}$ sistemlerin hassasiyet ve doğruluğu, kameranın kalitesinden ve görüntü oluşturma metodundan etkilenir. Birçok çalışma dijital kameraların uygun kalibrasyon protokolleriyle, diş ve dişeti rengi belirlemede güvenilir cihazlar olduğunu rapor etmiştir. ${ }^{36,38,39}$

Dijital fotoğrafların son dönemlerde popülaritesi artmasına rağmen, görüntü kalitesi oldukça önemlidir. Görüntü kalitesi ise; kameranın tipi, kameranın ayarları, ortamın aydınlanma koşulları, görüntünün boyutu, ilgili dişin pozisyonu ve renk anahtarına bağlı olarak değişebilmektedir. Dijital fotoğraflar ancak uygun koşullarda ve uygun cihazlarla ölçüm yapıldığında yararlı olabilecek renk değerlendirme yöntemleri olduğu düşünülmektedir. Ayrıca fotoğraftan elde edilen değerlendirmelerin tamamen subjektif olduğu ve yeterli olmayabileceği de görüşler arasındadır. $^{40}$

Dijital Kameraların Avantajlart: Sistemin en önemli avantajı tek bir noktanın değil tüm objenin renk görünümünün elde edilebilmesidir. ${ }^{35}$ Hekim ve teknisyenin ayr bina, şehir veya ülkelerde olduğu durumlarda dijital fotoğrafların kullanımı, hekim ve teknisyen iletişimini kolaylaştıran etkili bir yöntemdir. ${ }^{5}$

Dijital Kameralarm Dezavantajlarl: $\quad$ Tek başına kullanıldığında renk analizi için güvenilir bir yöntem değildir. Aydınlatma ve fotoğraf alınırken kullanılan açı rengin kamera tarafindan algılanmasını etkileyebilir. ${ }^{25}$ Fotoğraftan elde edilen değerlendirmelerin tamamen subjektif olduğu ve yeterli olmayabileceği de görüşler arasındadır. ${ }^{41}$ 


\section{Renk Analiz Verilerinin Uygulanması ve Yorumlanması}

Diş yüzeyini ölçen cihazlar gingival, gövde ve insizal tonların direk ve indirek üretim için renk haritasını verir. Çekilmiş dişleri incelerken spektrofotometre ve spektroradyometredeki pencere büyüklüğünü azaltmak daha düşük CIE L*a*b* değerleriyle sonuçlanır. Küçük pencereli diş rengi ölçümü dişin translusensine doğru olan 1şığın kenar kaybına neden olabilir. ${ }^{42}$

Referans fotoğraflar diş rengindeki iletişimde yüksek oranda önerilir. Dijital fotoğraflar, renk tonu ve renk haritalarıyla birlikte laboratuar teknisyenine önemli eklerdir ve kabul edilebilir bir restorasyon oluşturulmasında yeterli bağlantı olmalıdır. Dijital kameralar, görüntülerin klinisyenden teknisyene transferine izin verir.

Renk tonu bilgisini referans almanın en iyi yolu rengi iletmekte renk tonu şeritlerini kullanmaktır. ${ }^{6}$ İstikrarlı bir renk tonu iletişimi için kamera, 1şık ayarları ve görüntü formatı her zaman sabit tutulmalıdır. ${ }^{43}$

\section{SONUÇ}

Birçok faktör rengin algılanmasını etkileyebilir. Günümüz teknolojisiyle rengin değerlendirilmesindeki subjektiflik azaltılabilmiş ve restorasyon renginde doğru teşhis kolaylaşmıştır. Mümkün olduğunda hem instrumental hem de görsel renk eşleştirilmesi metodu kullanılmalıdır; çünkü bunlar birbirini tamamlamakta ve daha estetik sonuçlara ulaşılabilmektedir.

\section{KAYNAKLAR}

1. Saraç D, Saraç YŞ, Yüzbaşıŏglu E. Farklı kompozitlerle bir renk skalası arasındaki renk farklılıkları. GÜ Diş Hek Fak Derg 2005; 22: 77-82.

2. Okubo SR, Kanawati A, Richards MW, Childress S. Evaluation of visual and instrumental shade matching. J Prosthet Dent 1998; 80: 642-8.

3. Van Der Burgt TTP, Ten Borsch JJ, Borsboom PC, Kortsmit WJ. A comparison of new and conventional methods for quantification of tooth color. J Prosthet Dent 1990; 63:155-62.

4. Rosenstial SF, Land MF, Fujimoto J. Contemporary fixed prosthodontics, 4 ed. St. Louis; The CF Mosby Company: 2001. p.70939.

5. Pascal M, Besler U. Bonded porcelain restorations in the anterior dentition: a biomimetic approach. Chicago; Quintessence Publishing Co: 2002. p.179-238.

6. Fondreiest J. Shade matching in restorative dentistry: the science and strategies. Int J Periodontol Restor Dent 2003; 23: 46779.

7. Sproull RC. Color matching in dentistry. Part II: Practical applications of the organization of color. J Prosthet Dent 1973; 29: 556-66.

8. Seghi RR, Hawlett ER, Kim J. Visual and instrumental colorimetric assessments of small color differences on translucent dental porcelain. J Dent Res 1989; 68: 1760-4.

9. Swepston JH, Miller AW. Esthetic matching. J Prosthet Dent 1994; 54: 623-4.

10. Tashkandi E. Consistency in color parameters of a commonly used shade guide. Saudi Dent J 2010; 22: 7-11.

11. Wasson W, Schuman N. Color vision and dentistry. Quintessence of Dental Technology 1992. p: $1-10$

12. Paravina RD, Powers JM. Esthetic Color Training in Dentistry., 1th ed., St. Louis; Elsevier Mosby 2004. Ch:1-4, p.3-61.

13. Doğan A, Yüzügüllü B. Renk seçiminde güncel teknolojik gelişmeler. Atatürk Üniv Diş Hek Fak Derg 2011; 4: 65-72. 
14. Lee YK, Lim BS, Kim CW, Powers JM. Comparison of color of resin composites of white and translucent shades with two shade guides. J Esthet Restor Dent 2001; 13: 179-86.

15. Kim-Pusateri S, Brewer JD, Davis EL, Wee AG. Reliability and accuracy of four dental shade- matching devices. J Prosthet Dent 2009; 101: 93-199.

16. Bayındır F, Wee A. Diş rengi seçimine bilgisayar destekli sistemlerin kullanımı: derleme. HÜ Diş Hek Fak Derg 2006; 30: 406.

17. Tung FF, Goldstein GR, Jang S, Hittelman E. The repeatability of an intraoral dental colorimeter. J Prosthet Dent 2002; 88: 585-90.

18. Touati B, Miara P, Nathason D. Esthetic Dentistry and Ceramic Restorations. London: Martin Dunitz Ltd. 1st Ed. 1999. Ch.3-5 p.2561.

19. Schmitter $M$, Musotter $K$, Hassel A. Interexaminer reliability in the clinical measurement of $\mathrm{L}^{*} \mathrm{c} * \mathrm{~h} *$ values using a laminar spectrophotometer. Int J Prosthodont 2008; 21: 422-24.

20. Park J, Lee YK, Lim BS. Influence of illuminants on the color distrubition of shade guides. J Prosthet Dent 2006; 96: 402-11.

21. Keyf F, Uzun G, Altunsoy S. Diş hekimliğinde renk seçimi. HÜ Diş Hek Fak Derg 2009; 33: 52-8.

22. Brewer JD, Wee A, Seghi RR. Advances in color matching. Dent Clin North Am 2004; 48: 341-58.

23. Wee AG, Kang EY, Johnston WM, Seghi RR. Evaluating porcelain shade matching systems. J Esthet Restor Dent 2000; 12: 27180.

24. Khurana R, Tredwin CJ, Weisbloom M, Moles DR. A Clinical evaluation of the individual repeatability of three commercially avalible color measuring devices. Br Dent $\mathrm{J}$ 2007; 203: 675-80.

25. Chu SJ, Devigus A, Mieleszko A. Fundementals of Color. 1th ed., Quintessence Publishing 2004. Ch:1-4 p: 1-100.

26. Aladağ A, Çömlekçioğlu E, Yılmaz G. Farklı renk anahtarlarının metal kronların renk uyumlarına etkisi. Süleyman Demirel Üniv Diş Hek Fak 2009; 1: 8-17.

27. Paul S, Peter A, Pietrobon N, Hammerle $\mathrm{CH}$. Visual and spectrophotometric shade analysis of human teeth. J Dent Res 2002; 81: $578-82$.

28. Da Silva JD, Park SE, Weber HP, Ishikawa-Nagai S. Clinical performance of a newly developed spectrophotometer system on tooth color reproduction. J Prosthet Dent 2008; 99: 361-8.

29. Witkowski S, Yajima ND, Wolkowitz M, Strub JR. Reliabilty of shade selection using an intraoral spectrophotometer. Clin Oral Invest 2012; 16: 945-9.

30. Ristic I, Paravina RD. Color measuring instruments. Acta Stomatologica Naissi. 2009; 25: 925-32.

31. Dozic A, Kleverlaan CJ, El-Zohainy A, Feilzer AJ, Khashayar G. Performance of five commercially available tooth color measuring devices. J Prosthodont 2007; 16: 93-100.

32. Yuan K, Sun X, Wang F, Wang H, Chen $\mathrm{JH}$. In vitro and in vivo evaluations of three computer-aided shade matching instruments. Oper Dent 2012; 37: 219-27.

33. Lasserre JF, Pop-Ciutrila IS, Colosi HA. A comparison between a new visual method of colour matching by intraoral camera and conventional visual and spectrometric methods. J Dent 2011; 39: 29-36.

34. Jarad FD, Russel MD, Moss BW. The use of digital imaging for colour matching and communication in restorative dentistry. $\mathrm{Br}$ Dent J 2005; 199: 43-49. 
35. Lath DL, Wildgoose DG, Guan YH, Lilley TH, Smith RN, Brook AH. A digital image analysis system for the assessment of tooth whiteness compared to visual shade matching. J Clin Dent 2007; 18: 17-20.

36. Wee AG, Lindsey DT, Kuo S, Johnston WM. Color accuracy of commercial digital cameras for use in dentistry. Dent Mater 2006; 22: 553-9.

37. Blaes J. Today's technology improves the shade-matching problems of yesterday. J Indian Dent Assoc 2003; 81:17-9.

38. Sagel PA, Gerlach RW. Application of digital imaging in tooth whitening randomized controlled trials. Am J Dent 2007; 20: 7A-14A.

39. Bayindir F, Bayindir YZ, Gozalo-Diaz DJ, Wee AG. (2009). Coverage error of gingival shade guide systems in measuring color of at tached anterior gingiva. J Prosthet Dent 2009; 101: 46-53.

40. Karamouzos A, Papadopoulos MA, Kolokithas G, Athanasiou AE. Precision of in vivo spectrophotometric color evaluation of natural teeth. J Oral Rehabil 2007; 34: 613-21.
41. Silva J, Park S, Weber HB, Shigemi IN. Clinical performance of a newly developed spectrophotometric system on tooth color reproduction. J Prosthet Dent 2008; 99: 361-8.

42. Bolt RA, Ten Bosch JJ, Coops JC. (1994). Influence of window size in small-window measurements, particularly of teeth. Phys Med Biol 1994; 39: 1133-42.

43. Ishikawa-Nagai S, Yoshida A, Da Silva JD, Miller L. Spectrophotometric analysis of tooth color reproduction on anterior allceramic crowns. Part 1. Analysis and interpretation of tooth color. J Esthet Rest Dent 2010; 22: 42-52.

\section{Yazışma Adresi}

Tuğba ÇONGARA KIVRAK

Ankara Üniversitesi

Diş Hekimliği Fakültesi

Diş Hastalıkları ve Tedavisi Anabilim Dalı

Ankara, Türkiye.

Tel: 05056469652

Fax:0312 2123954

E-posta: tugbacongara@hotmail.com 